Western University Scholarship@Western

Department of Economics Research Reports

Economics Working Papers Archive

1988

\title{
Tax Incidence in a Hierarchical Model
}

Kul B. Bhatia

Follow this and additional works at: https://ir.lib.uwo.ca/economicsresrpt

Part of the Economics Commons

Citation of this paper:

Bhatia, Kul B.. "Tax Incidence in a Hierarchical Model." Department of Economics Research Reports, 8801. London, ON:

Department of Economics, University of Western Ontario (1988). 


\section{ISSN : 0318-725X}

ISBN : 0-7714-0984-2

RESEARCH REPORT 8801

\section{TAX TNCIDENCE IN A HIERARCHICAL MODEL}

Kul B. Bhatia

Department of Economics

University of Western Ontario

London, Ontario, Canada

N6A $5 C 2$

Harch 1988

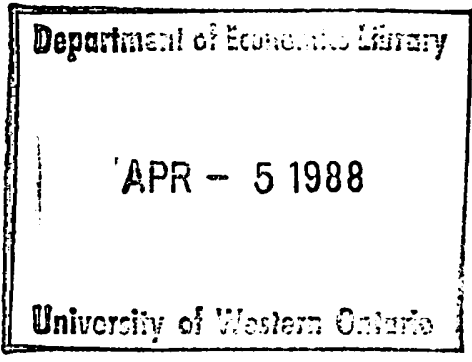


TAX INCIDENCE IN A HIERARCHICAL HODEL

\author{
Kul B. Bhatia
}

March 1988

\author{
Department of Economics \\ University of Western Ontario \\ London, Ontario N6A 5C2 \\ Canada
}


TAX INCIDENCE IN A HIERARCHICAL MODEL

\begin{abstract}
Production hierarchies are common in input-output tables but have not been used much in analytical work on tax incidence. A general equilibrium model with two mobile factors and flexible production coefficients is set up for this purpose. Earlier studies generally assumed one factor and fixed coefficients. There is one intermediate good, a final good, and one with both final and intermediate uses. Some features of existing models with intermediate and final goods carry over to hierarchical technology, but results about incidence of factor and commodity taxes differ markedly even under severe restrictions on elasticities of substitution and other parameters.
\end{abstract}

Kul B. Bhatia

Department of Economics University of Western Ontario London, Ontario, Canada N6A $5 \mathrm{C2}$ 


\section{Introduction}

The main objective of this paper is to consider incidence of various taxes when production is organized in a hierarchical fashion. A production hierarchy is one in which some industries have backward and forward linkages. For example, a steel mill purchases iron ore from a mining company and supplies steel to an automobile manufacturer which then sells cars to final consumers, or an oil company, using drill bits and other equipment produced by the steel industry, pumps crude oil which, after refining, is used by final consumers or by some other industries. According to this definition, a large number of industries in many countries have a hierarchical technology in one form or another. Some activities have a rather simple structure, with one or two linkages, while others are connected with many different industries in a complex pattern. The definition refers to organization of production, not to ownership or control. Therefore, if a steel company acquires a mine and then merges with an auto manufacturer, the hierarchy does not disappear.

It is generally not a simple matter to analyze incidence of taxes levied on, say, steel or gasoline in a hierarchical set-up because taxes will be carried over from one industry to another, and there is always the possibility of tax pyramiding if more than one tax is present in the system or several interlinked industries are subject to the same tax. One way of avoiding this problem is to somehow exempt inter-firm transactions, but that is not an easy task, administratively, and for some taxes, such as a corporation income tax (CIT), it might be difficult to determine how much of the tax is being passed on.

In spite of the popularity of production hierarchies, they have not been considered much in the tax literature. A value-added tax (VAT) is typically 
treated in terms of a manufacturing-wholesale-retail arrangement in public finance textbooks and in popular discussion (Harberger(1966), McLure (1981)), but other taxes, especially factor taxes, have not been examined much. The only rigorous treatment is due to Friedlaender (1967) who analyzed the effects of several indirect taxes on output prices, and Atkinson and stiglitz (1980) briefly discussed a tax on labor in that framework. That model assumes fixed production coefficients and only one factor of production, labor, which unduly limits the range of taxes and issues that can be adequately considered. The production structure in this paper assumes flexibility of all coefficients, two factors of production, and three industries which are interlinked in many ways. Both factor- and commodity taxes can be discussed without any prior restrictions, and one can also ask how the constricting assumptions made in earlier studies affect the final results. Although such flexible hierarchies have not received much attention, this is by no means uncharted terrain, for in the final analysis a hierarchy is built around intermediate goods which have been incorporated in many models, especially in the fields of international trade and taxation. There are pure intermediate goods (PIGs), i.e. goods without any use in final demand, and those which are used both as intermediate inputs and final goods. The latter are the backbone of every ananlytical study involving an input-output framework, the two factor-two- commodity model in Warne (1971) from international trade theory for example, or a similar specification in Bhatia (1982) for various taxes. A hierarchy, as a minimum requirement, includes both types of intermediate goods, and that has not been done in rigorous analysis of taxes so far except in the very restrictive Friedlaender framework mentioned above. 
Existing models do help in understanding the role of intermediate goods, but their inadequacy becomes all too apparent in any actual input-output table. To take two examples, U.S.A. and Malaysia, a developed and a developing country, hardly one or two goods qualify as PIGs in their i-o tables, and there are not many pairs of goods whose output is exhausted by intermediate usage in each other and by final demand, as is postulated in much earlier work ${ }^{1}$. That leaves large scale models used for numerical computations which incorporate all types of goods (Fullerton, Shoven and Whalley (1978) for instance), but they invariably assume fixed coefficients or impose other restrictions on elasticities of substitution which undermine the generality of their conclusions. Effects of such restrictions cannot be gauged without adopting a more flexible approach.

Another advantage of the present model is that it is also possible to consider how different features and results of PIG and i-o models fare in a more complex production structure. For example, whenever intermediate inputs are used, gross and net factor intensities differ. In an i-o model, industries have the same rank in gross and net terms, but not necessarily so when only PIGs are present (Batra (1974)). Many results about tax incidence in the literature depend on this important distinction between the two types of models. With respect to factory intensities, the hierarchy set up here is like a PIG model, yet results differ, and they contrast even more sharply with those in final-goods-only (FGO) models. A good example is the famous result due to Harberger (1962) that in an FGO model, labor can suffer from CIT only if the taxed industry is relatively labor intensive. This necessary condition must apply in gross terms when an untaxed PIG is introduced (Bhatia (1982)), but in the present model, the wage-rental ratio might fall even when a taxed 
industry is relatively capital intensive if it has forward linkages. Many other conclusions of this sort will emerge in the following analysis.

The model is set out in the next section. Some taxes are incorporated into the theoretical framework in Section 3 where the model is also solved. Results about tax incidence are derived in Section 4, and the main conclusions are sumnarized in section 5 .

\section{The Theoretical Framework}

Let there be three goods, $x_{1}, x_{2}$, and $x_{3}, x_{1}$, at the base of the hierarchy, is used up entirely in producing $x_{2}$. A portion of $x_{2} \cdot s$ output, $x_{23}$, is used by $x_{3}$ as an intermediate input; the rest, $x_{2}$, and $x_{3}$ satisfy final demand. Among the three commodities, thus, one is a pure final good, another a pure intermediate good, and the third has both intermediate and final uses. $x_{2}$, with both forward and backward linkages, is the kingpin of this hierarchy, and it captures rather well the complications caused by hierarchical technology. Such goods, however, have not appeared in a general theoretical model of tax incidence so far, although economic functions of all three types of goods have been featured here and there. For instance, Warne (1971), and many other trade and taxation models have goods with both intermediate and final uses, but no pure intermediate goods. Hany PIG models have a pure intermediate input and two final goods, again without anything like $\mathrm{x}_{2}$. This is a curious omission considering that goods of that type abound in input-output models of many countries. Often they are the most common category, yet we know the least about incidence of taxes imposed on them.

Production of all goods depends on intermediate inputs and the two 
primary factors, labor and capital, which are assumed to be in fixed aggregate supply and fully employed. There is perfect competition in every market, and all production coefficients are flexible. The capital-labor ratio in $x_{1}$ is determined by the wage-rental ratio, $w / r$, whereas prices of intermediate inputs also will affect input choices in the other two industries.

\subsection{Direct and Total Factor Usage}

Because of the hierarchical structure of production, total capital and labor needed for producing $x_{2}$ and $x_{3}$ will be greater than the primary factors directly employed in these industries. For example, if $a_{L j}$ is the amount of labor directly needed for a unit of output $j$, the total requirement of labor for producing a unit of $x_{2}, R_{L 2}$, will be $a_{L 2}+a_{12} \cdot a_{L 1}$, where $a_{12}$ is simply $x_{1} / x_{2} \cdot R_{L 3}$, however, will be somewhat different because it will be indirectly using some of the labor employed in both $x_{1}$ and $x_{2}$, not just in the latter, so $R_{L 3}=a_{L 3}+a_{23} \cdot R_{L 2}$. Corresponding to direct and total factor usage are direct and total factor shares, $\rho s$ and $\theta s$, respectively. For instance, $\rho_{L 2}=w \cdot a_{L 2}$ whereas $\theta_{L 2}=\rho_{L 2}+\rho_{12} \cdot P_{L 1}$, and $\theta_{L 3}=\rho_{L 3}+\rho_{23} \cdot \theta_{L 2}$.

If $x_{3}$ uses some of $x_{1}$ directly as an intermediate input, in lieu of $\mathrm{x}_{2}$, the model will be a PIG model as in Bhatia (1982). If instead of $\mathrm{x}_{1}$, the two final goods simply use each other as intermediate inputs, we shall get the standard i-o model. In both these cases, definitions of $R_{L 2}$ and $R_{L 3}$ will be symmetrical. Here, the two are asymmetrical, which is a hallmark of the present hierarchy that distinguishes it from production structures of other models with intermediate goods. At first glance, this does not appear to be a major distinction, but it affects almost all the equations on the 
supply side of the model, as we shall see presently, and it undoubtedly accounts for many of the new results derived in the paper.

The hierarchical structure here is a hybrid of a PIG and an i-o model. It is well known that the latter two models differ in terms of their relationship between direct and total usage of primary factors: in a PIG model, an industry can be relatively capital intensive in terms of direct capital-labor ratios, but labor intensive when both direct and indirect usage are considered. As an example, in the present framework, as well as in a PIG model, $a_{L 2}$ might be greater than $a_{L 3}$ while $R_{L 2}<R_{L 3}$. Such factor-intensity reversal is not possible in an $i-0$ model because industries must have the same rank in gross and net terms. In this regard, the production structure here is like a PIG model even though one of the goods, $\mathrm{x}_{2}$, has a partial i-o linkage. This feature will figure prominently in many of the tax-incidence results to be derived later.

A number of equations can be specified now.

$$
\begin{aligned}
& \theta_{L 22^{*}}+\theta_{K 2} r^{*}=p_{2}^{*} \\
& \theta_{\mathrm{L} 3} \mathrm{w}^{*}+\theta_{\mathrm{K} 3} \mathrm{r}^{*}=\mathrm{p}_{3}^{*}
\end{aligned}
$$

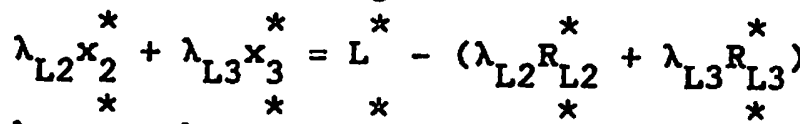

$$
\begin{aligned}
& \lambda_{\mathrm{K} 2} \mathbf{x}_{2}^{*}+\lambda_{\mathrm{K} 3} \mathbf{x}_{3}^{*}=\mathrm{K}^{*}-\left(\lambda_{\mathrm{K} 2} \mathrm{R}_{\mathrm{K} 2}^{*}+\lambda_{\mathrm{K} 3} \mathrm{R}_{\mathrm{K} 3}^{*}\right)
\end{aligned}
$$

In these equations, asterisks denote proportional changes, and $\lambda_{i j}$ is the proportion of the $i_{\text {th }}$ primary factor used directly or indirectly in industry j. Thus, $\lambda_{L j}=R_{L j} / L$, etc. Equations (1) and (2) are the zero-profit conditions for cost-minimizing firms in competitive equilibria, while the assumptions of full-employment and fixed factor endowments are reflected in (3) and (4). Since the focus is on the structure of production, a simple demand function, which has been used in many general equilibrium models of tax incidence, is specified in (5). 


$$
x_{2}^{*}=c\left(p_{2}^{*}-p_{3}^{*}\right), \quad \varepsilon<0
$$

where $\varepsilon$ is the income-compensated elasticity of demand for $x^{2} .2$

Let us now discuss specific taxes in various industries.

\section{Taxes in Hierarchical Production}

The three industries differ a good deal in how individual taxes affect them and the rest of the economy. The same tax will have rather different repercussions, depending on whether it is levied on $x_{1}, x_{2}$, or $x_{3}$. Any tax on $x_{1}$ will be carried forward to $x_{2}$ and $x_{3}$, creating, in effect, three taxed industries with possibly different effective tax rates. At the other extreme, a factor or a commodity tax on $x_{3}$ will not affect any other industry unless input prices change, whereas a $\operatorname{tax}$ on $x_{2}$ will directly affect $x_{3}$ but not $x_{1}$.

starting from a given equilibrium, at unchanged factor prices, a commodity $\operatorname{tax}$ on $x_{1}$ will not affect the capital-labor ratio in that industry. In $x_{2}$, however, it will have the effect of a partial factor tax because one of the input prices, $p_{1}$, will have risen, and likewise in $x_{3}$. Whether $w$ and $r$ eventually adjust depends on what happens to demand for labor and capital, and that will be determined by changes in output and factor intensities in each industry. ${ }^{3}$ For ease of exposition, we deal with netand gross factor intensities first, recognizing, of course, that all other adjustments must also take place, perhaps simultaneously, as the economy moves to a new equilibrium.

\subsection{Changes in Factor Intensities}

In $x_{1}$, change in the capital-labor ratio can be simply seen from the definition of elasticity of substitution, $\sigma_{K L}^{I}$, for $a_{K I}^{*}-a_{L I}^{*}=\sigma_{K L}^{1}\left(w^{*}-r^{*}\right)$, 
and the commodity $\operatorname{tax}$ on $x_{1}$ will not directly affect $a_{K 1}$ and $a_{L I}$.

In the other two industries the situation is more complicated because each of them has three inputs, labor, capital and an intermediate good, which implies that there are three relative input prices and nine partial elasticities of substitution. 4 Moreover, both direct and total factor requirements $\left(a_{i j} s\right.$ and $R_{i j} s$ ) have to be taken into account. In $x_{2}$, for example, $a_{L 2}$ is a function of $w, r$, and $p_{1}$. Assuming this function to be homogeneous of degree zero in input prices, by totally differentiating it and simplifying we get: 5

$$
a_{L 2}^{*}=-\left[\rho_{12} \rho_{K 1} \sigma_{L 1}^{2}+\rho_{K 2} \sigma_{L K}^{2}\right]\left(w^{*}-r^{*}\right)+\rho_{12} \sigma_{L 1}^{2} T_{1}^{*}
$$

It follows that proportional change in labor per unit of output directly used in $x_{2}$ depends on two elasticities of substitution, $\sigma_{L 1}^{2}$ and $\sigma_{L K}^{2}$. If the wage-rental ratio remains constant, $\left(w^{*}-r^{*}\right)$ equals zero, and only the elasticity of substitution between labor and $x_{1}$ in $x_{2}$, along with the tax rate, will matter. These remarks, mutatis mutandis, apply to other $a_{i j}^{\star} s$ as well.

Turning to changes in total factor requirements, the expressions become more elaborate. For example (see Appendix for details),

$$
R_{L 2}^{*}=-\frac{B_{2}+P_{12} \alpha_{1}}{\theta_{L 2}}\left(w^{*}-r^{*}\right)-\frac{P_{12} A_{2}}{\theta_{L 2}} T_{1}^{*}
$$

where $B_{2}=\rho_{\mathrm{K} 1}^{2} \rho_{L 2} \rho_{12} \sigma_{L 1}^{2}+\rho_{L 22} \rho_{K 2} \sigma_{L K}^{2}+\rho_{L 1}^{2} \rho_{K 2} \rho_{12} \sigma_{K 1}^{2}$

$$
\alpha_{1}=\rho_{K 1} \rho_{L 1} \sigma_{L K}^{1} \text {, and } A_{2}=\left(\rho_{L 1} \rho_{K 2} \sigma_{K 1}^{2}-\rho_{L 2} \rho_{K 1} \sigma_{L 1}^{2}\right) \text {. }
$$

Now all elasticities of substitution, both in $x_{1}$ and $x_{2}$, affect changes in total labor-output ratio, which is understandable because if $w / r$ alters, the labor-output ratio in $x_{1}$ will change, and $a_{L 2}$ and $a_{12}$ will also adjust, 
influenced, undoubtedly, by the elasticities of substitution in $x_{2}$. If the wage-rental ratio is constant, $\mathrm{R}_{\mathrm{L} 2}^{*}$ will be determined mainly by $\sigma_{\mathrm{K} 1}^{2}$ and $\sigma_{\mathrm{L} 1}^{2}$, the elasticities of substitution involving $x_{1}$ as an intermediate good in $x_{2}$.

Output of $x_{3}$ is determined by labor $\left(L_{3}\right)$, capital $\left(K_{3}\right)$, and $x_{23}$, the portion of $x_{2}$ that is used as an intermediate input in $x_{3}$. There are thus possibilities of substituting labor for capital, and the primary factors for the intermediate good. Consequently, the $R^{*} s$ in $x_{3}$ will depend on everything that affects $R_{L 2}^{*}$ and $R_{K 2}^{*}$, and on additional elasticities of substitution in $x_{3}$. For instance,

$$
R_{L 3}^{*}=\left[\theta_{L 2} \rho_{23}\left(a_{23}^{*}+R_{L 2}^{*}\right)+\rho_{L 3} a_{L 3}^{*} T_{1}^{*}\right] / \theta_{L 3}
$$

which simplifies to

$$
\left[\left\{B_{3}+P_{23}\left(B_{2}+P_{12} \alpha_{1}\right)\right\} r^{*}-P_{23} A_{2}-P_{12} A_{3}\right] / \theta_{L 3}
$$

where $B_{3}=\rho_{K 2} \rho_{23} \rho_{L 3} \theta_{K 2} \sigma_{L 2}^{3}+\rho_{L 2} \rho_{23} \theta_{L 2} \rho_{K 3} \sigma_{K 2}^{3}+\rho_{L 3} \rho_{K 3} \sigma_{L K}^{3}$

$$
A_{3}=\rho_{23}\left(\theta_{K 2} \rho_{23} \sigma_{K 2}^{3}-\theta_{L 2} \rho_{K 3} \sigma_{L 2}^{3}\right) \text {, and } \alpha_{1} \text { and } B_{2} \text { have been already }
$$

defined. It is obvious that $B_{3}$ is a weighted sum of various elasticities of substitution in $x_{3}$, analogous to $B_{2}$ for $x_{2}$. Whenever some of the os are zero, the expressions for $a^{\star} s$ and $R^{\star} s$ will be simplified accordingly.

Expression ( 8 ) shows the production hierarchy in its full complexity. Proportional change in total labor required for producing a unit of $x_{3}$ depends on factor shares and elasticities of substitution in all three industries. The excise tax is levied on $x_{1}$, but it affects factor 
intensities everywhere else, even at a constant wage-rental ratio. other taxes of course will lead to different conclusions in this regard, and there will be many instances of that in the rest of the paper. A factor tax in $x_{1}$, for example, will affect factor intensities in every industry, including $x_{1}$, wherever production coefficients are flexible.

Because of the rather simple demand structure, burden of various taxes in this model is confined to the production or sources side of the economy where factor shares hold the key. If $w / r$ remains constant, relative factor shares do not change due to the assumptions of full employment and fixed factor supplies. Labor and capital, therefore, bear the tax burden in proportion to their initial contribution to national income. Compared to this benchmark, the factor that becomes relatively cheaper is affected more. The model, therefore, has to be solved for changes in the wage-rental ratio, or for $\left(w^{*}-\Gamma^{*}\right)$.

\subsection{Solving the Model}

The basic step involved in solving the model is to determine $x_{2}^{*}$ from the supply side equations and then equate it to the corresponding demand equation (5). This procedure can be simplified by setting initial prices to unity by appropriate choice of units, and by choosing the wage rate, $w$, as the numeraire, which implies that w* becomes zero everywhere, so $r^{\star}$ denotes proportional changes in $w / r$. Let us continue with the case of a commodity tax on $\mathrm{x}_{1}$.

On the supply side, after setting $L^{*}=K^{*}=0$ in (3) and (4) because of the assumption of fixed factor endowments, we get: 


$$
x_{2}^{*}=\frac{\lambda_{L 3} \lambda_{K 2} R_{K 2}^{*}-\lambda_{L 3} \lambda_{L 2} R_{L 2}^{*}+\lambda_{L 3} \lambda_{K 3}\left(R_{K 3}^{*}-R_{L 3}^{*}\right)}{\lambda_{L 2} \lambda_{K 3}-\lambda_{K 2} \lambda_{L 3}}
$$

Now substitute for the $R^{*} s$ which, after simplification, yields the final expression for $x_{2}^{*}($ supply):

$x_{2}^{*}=-\left[\left(B_{2}+p_{12} \alpha_{1}\right) B+\frac{\lambda_{L 3}{ }^{\lambda} K 3}{\theta_{L 3} \theta_{K 3}} B_{3}\right] r^{*}+\left(B_{2}+\frac{\lambda_{L 3} \lambda_{K 3}}{\theta_{L 3} \theta_{K 3}} A_{3}\right) T_{1}{ }^{*} /\left(\lambda_{L 2} \lambda_{K 3}-\lambda_{K 2} \lambda_{L 3}\right)$

where $\quad B=\frac{1}{\theta_{K 2}} \frac{\lambda_{L 3}}{\lambda_{L 2}}+\frac{1}{\theta_{L 2}} \frac{\lambda_{L 3} \lambda_{K 3}}{\theta_{L 2}{ }{ }_{K 3}}$, and $\alpha_{1}, B_{2}, B_{3}, A_{2}$ and $A_{3}$

have been defined above.

On the demand side, after substituting for $p_{2}^{*}$ and $p_{3}^{*}$ into (5)

we get:

$$
x_{2}^{*}=\varepsilon\left[\left(\theta_{K 2}-\theta_{K 3}\right) r^{*}+\rho_{12}\left(1-\rho_{23}\right) T_{1}^{*}\right] .
$$

And by equating $x_{2}^{*}$ (supply) to $x_{2}^{*}$ (demand), from (10) and (11), we get:

$$
r^{*}=\frac{\varepsilon \rho_{12}\left(1-\rho_{23}\right) F+B A_{2}+\rho_{12} A_{3} \lambda_{L 3} \lambda_{K 3} / \theta_{L 3} \theta_{K 3}}{D} T_{1}^{*}
$$

where $D=c\left(\theta_{K 3}-\theta_{K 2}\right) F+\left(B_{2}+\rho_{12} \alpha_{1}\right) B+\frac{\lambda_{L 3} \lambda_{K 3}}{\theta_{L 3} \theta_{K 3}} B_{3}$, and $F=\left(\lambda_{K 2} \lambda_{L 3}-\lambda_{K 3} \lambda_{L 2}\right.$

The denominator of $\mathbf{r}^{*}, D$, will occur again and again, for every tax that is analyzed. It is therefore useful to establish its sign once and for all. Of the three terms in $D$, the last two will always be positive. If all os are non-negative, it can be determined from the definitions of $B_{2}$ and $B_{3}$ that they will be positive. However, even when some os are negative, which indicates complementary inputs, it can be shown that these terms will 
still be positive. 6 The first, involving $\varepsilon$, appears to have an ambiguous sign, but it too is positive because $\varepsilon<0$, and $\left(\theta_{\mathrm{K} 3}-\theta_{\mathrm{K} 2}\right)$ and $\left(\lambda_{\mathrm{K} 2} \lambda_{\mathrm{L} 3}-\lambda_{\mathrm{K} 3} \lambda_{\mathrm{L} 2}\right)$. always have opposite signs. For example, if $x_{2}$ is relatively capital intensive, $\theta_{\mathrm{K} 2}>\theta_{\mathrm{K} 3}$, and the $\lambda$-term, which can be written as $\left(K_{2} / L_{2}-K_{3} / L_{3}\right) / L K$, will be positive. It follows that the denominator in (12) will always be positive. The sign of $r^{*}$, thus, will depend on the terms in the numerators of such expressions for various taxes.

\section{Tax Incidence Results}

For each tax we shall derive expressions such as (12) and examine them for general results which will then be compared with the results in other models wherever possible. Factor taxes in a PIG industry such as $\mathrm{x}_{1}$ have not been examined at all in the literature. The case of an excise tax was briefly discussed in Bhatia (1982), but there the intermediate good was used directly in producing the two final goods whereas here it is first imbedded in $x_{2}$ before being used by the other final good. This will turn out to be a very important difference when results of the two models are compared.

\subsection{Excise Tax on $\mathrm{x}_{1}$ \\ The sign of $r^{\star}$ in (12) depends on relative factor intensity, based on} total factor usage in the two final-good industries, as well as on elasticities of substitution involving intermediate goods throughout the economy. If $x_{1}$ and $x_{2}$ must be used in fixed proportions in producing $x_{2}$ and $x_{3}$, respectively, $A_{2}$ and $A_{3}$ will be zero, and $r^{*}$ will be positive or negative according to whether $x_{3}$ is more or less capital intensive than $x_{2}$. Many propositions about tax-incidence can be derived by examining 
individual terms in (12) and placing restrictions on various parameters, but more can be learnt by comparing this equation with the results in earlier, related models.

\subsubsection{Comparison with FGO models}

One of the most well-known propositions in tax incidence theory, derived formally by Mieszkowski (1967) from the Harberger model with only final goods, is that the incidence of a partial excise tax depends on the capital-labor ratio in the taxed industry, and on the elasticity of demand for its products. In the notation adopted in this paper, $r^{*}=\varepsilon F / d$, where $d$, still positive, is a truncated version of the denominator of equation (12). The first thought to cross one's mind on seeing (12) is the length and complexity of that expression, in stark contrast with Mieszkowski's simple result. In particular, neither the capital-labor ratio in the taxed industry, nor elasticity of demand for its output has any direct role to play in determining the sign of $\mathbf{r}^{*}$. It might well happen that the taxed good is relatively capital intensive, which will make $r^{*}$ negative in Mieszkowski's expression, yet $x_{3}$ has a higher capital-labor ratio than $x_{2}$ in the production hierarchy, so $r^{*}$ turns out to be positive in equation (12) if, for example, all elasticities of substitution in $x_{2}$ and $x_{3}$ are zero. If the model has only final goods, no elasticity of substitution has any effect on the sign of $r^{*}$ when an excise tax is levied.

Turning to elasticity of demand, if demand for final goods is inelastic, $r^{*}$ will be zero in Mieszkowski's expression, whereas in the present case, the wage-rental ratio normally would change. With inelastic demand, or equal capital-labor ratios in $x_{2}$ and $x_{3}$, the wage-rental ratio will remain 
constant so long as all intermediate goods are used in fixed ratios. These conclusions, of course, are a reflection of the more elaborate and flexible production structure of the hierarchical model. There will nonetheless remain one common result between Mieszkowski's FGO model and the one here: an infinite elasticity of capital-labor substitution in any industry will lead to a constant wage-rental ratio. These elasticities occur only in the denominator of $r^{*}$. In the FGo model, as $\sigma_{\mathrm{KL}}^{1}$ or $\sigma_{\mathrm{KL}}^{2}$ gets larger, $r^{*}$ goes to zero. The same result follows in the present case with $\sigma_{\mathrm{KL}}^{3}$ as well.

\subsubsection{Comparison with a PIG model}

Many of the points made above about the roles of elasticities of substitution and demand, relative factor intensities, and total factor usage apply whenever a PIG is taxed, regardless of the production structure of the rest of the model. In one respect, however, the hierarchical technology here is very different from the PIG model in Bhatia (1982) although it too has two primary factors and three goods. The importance of this point is seen most clearly when all interemediate goods must be used in fixed proportions.

In (12), when all os are zero, the sign of $r^{*}$ depends essentially on $F$, on gross capital-1abor ratios in the two final-good industries because $\mathbf{r}^{*}=$ ${ }^{e P_{12}}\left(1-P_{23}\right) F / D$. If $x_{1}$ were to be used directly in producing $x_{2}$ and $x_{3}$, we get the other model in which $F^{*}=\varepsilon\left(P_{12}-P_{13}\right) F / D$ (Bhatia (1982), equation (32), in comparable notation, where $\rho_{12}$ and $P_{13}$ are the shares of $x_{1}$ in the two final goods.) Whenever $F>0, r^{*}<0$ in (12). In the other model, however, $F$ and $\left(p_{12}-p_{13}\right)$ can easily have opposite signs. For example, when $x_{2}$ is more capital intensive than $x_{3}$ 
$(F>0)$, the share of $x_{1}$ in $x_{2}$ can be less than that in $x_{3}$, which will make $r^{*}$ positive. In this example, the sign of $r^{*}$ switches from negative to positive, and the only change we have made is to allow the final good $\left(x_{3}\right)$ to use some of the pure intermediate good $\left(x_{1}\right)$ directly rather than channeling all of it through the other good, $x_{2}$. It follows that even in very similar models, under highly restrictive conditions, hierarchical production can lead to strikingly different results.

\subsection{Factor taxes in $x_{1}$}

A tax on labor or capital in this industry can be analyzed in an analogous manner. Once again unit costs will be affected, output prices will change, expressions for $a_{i j}^{*} s$ and $R_{i j}^{*} s$ will be needed, which will eventually lead to a solution for $r^{\star}$, similar to that in equation (12). To limit the length of this paper, and to concentrate on the results, only the final solutions for $r^{*}$ are presented here.

\section{A tax on capital in $x_{1}\left(t_{K 1}\right)$}

$$
r^{*}=\frac{\varepsilon \rho_{12} \rho_{K 1}\left(1-\rho_{23}\right) F+\rho_{K 1}\left[B\left(A_{2}-\rho_{12} \rho_{L 1} \sigma_{L K}^{I}\right)+\rho_{12} \lambda_{L 3} \lambda_{K 3} A_{3} / \theta_{L 3} \theta_{K 3}\right]}{D} T_{K 1}^{*}
$$

A tax on labor in $\mathrm{X}_{1} \quad\left(t_{\mathrm{L} 1}\right)$

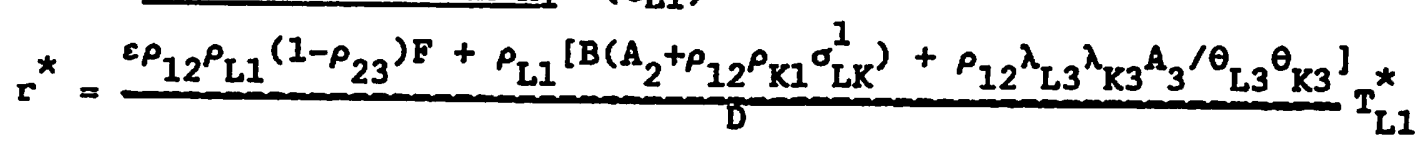

In the above expressions, $T_{K I}^{\star}$ and $T_{L I}^{*}$ represent proportional changes in the rate of tax on capital and labor, respectively. Here again elasticities of substitution involving intermediate goods affect the sign of $\mathbf{r}^{*}$. Either factor tax will alter the capital-labor ratio in $\mathrm{x}_{1}$, unlike the excise tax discussed above; therefore, $\sigma_{\mathrm{KL}}^{1}$, which now appears in 
the numerators of $r^{*}$ in (13) and (14), has an important role to play.

\section{Some general results}

Since factor taxes in a hierarchical framework have not been studied much in the literature, it is useful to examine them further. We focus on equation (13), a tax on capital, which is akin to Harberger's CIT in an FGO model although there is no final demand for $x_{1} .7$

In Harberger (1962), the sign of $r^{*}$ depends on elasticity of final demand, and on capital-labor ratio and elasticity of substitution in the taxed industry. All these terms appear in (13), but there is a good deal more. The capital-labor ratio in $x_{1}$ per se is not important; rather, gross

capital-labor ratios in the two final-good industries matter, and $\sigma_{\mathrm{K} 1}^{2}$, $\sigma_{L 1}^{2}, \sigma_{L 2}^{3}$, and $\sigma_{K 2}^{3}$ figure prominently. These elasticities reflect possibilities of substituting the primary factors for intermediate goods, so they have no counterpart in an FGO model. A number of general results can now be stated.

1. If all intermediate goods must be used in fixed proportions, capital will bear more of the tax in proportion to its share in national income if $\mathrm{x}_{2}$, which uses all of the taxed good, is relatively capital intensive. In this case, all elasticities of substitution involving $x_{1}$ and $x_{2}$ will be zero. By definition, $\sigma_{\mathrm{KL}}^{1}$ is positive, and if $x_{2}$ is relatively capital intensive, $F$ will be positive, so $\mathbf{r}^{\star}<0$. This results will actually hold under a somewhat weaker condition because, with $F>0, r^{*}$ will be negative whenever $A_{2}$ and $A_{3}$ are zero or negative in (13), and for that it is sufficient to have $\sigma_{\mathrm{K} 1}^{2}=\sigma_{\mathrm{K} 2}^{3}=0$. Elasticities of substitution between labor and the intermediate goods need not be zero. 
Explanation for a negative $r^{*}$ is straightforward. Due to the tax, labor will be substituted for capital in $x_{1}$ if possible, and its output will fall, which will release both capital and labor. All of $x_{1}$ is used in the production of $x_{2}$, and if $x_{1}$ must be used in fixed proportions with labor and capital, unit cost of $\mathrm{x}_{2}$ will go up, that industry will contract, and more labor and capital will be released. If $\mathrm{x}_{2}$ is relatively capital intensive in terms of total factor usage, there will be an excess supply of capital which will lead to a decline in its relative price.

2. If all factor proportions in the economy are fixed, demand elasticity will have no bearing on tax incidence. In this case, all terms except the first cancel out in both the numerator and denominator of (13), and $r^{*}=\rho_{12} \rho_{K 1}\left(1-\rho_{23}\right) /\left(\theta_{K 3}-\theta_{K 2}\right)$. If $x_{2}$ is relatively capital intensive, $r^{*}$ will be negative, and conversely.

3. If the two final-good industries have the same gross capital-1abor ratio, capital will bear proportionately more of the tax burden if it cannot be substituted for intermediate goods in $x_{2}$ and $x_{3}$. In this situation, the first term in both the numerator and denominator of (13) will vanish. The only parameters that can prevent $r^{*}$ from becoming negative are $\sigma_{\mathrm{K} 1}^{2}$ and $\sigma_{\mathrm{K} 2}^{3}$ which appear in the numerator with a positive sign, as components of $A_{2}$ and $A_{3}$, respectively. Therefore, if these os are zero, $r^{*}$ will be negative.

Economic explanation for this result is quite insightful. The intermediate goods embody "taxed capital" whose cost has gone up because of the tax. If it could be substituted for untaxed capital, i.e. capital directly employed in $x_{2}$ and $x_{3}$, other things being equal, there will be a smaller excess supply of capital, hence a lesser decline in its relative 
price. In the absence of such substitution possibilities, $r^{*}$ must be more negative. A similar argument will apply to elasticities of substitution between labor and the intermediate goods. Larger values of these os will be detrimental to the interests of capital.

A number of other results can be derived by examining (13) in greater detail, but perhaps it is sufficient to recognize here that the broad principle underlying most results is that the hierarchical technology imbeds the factor tax in $x_{1}$ into other industries which, in effect, use two types of capital: that directly employed by them is not taxed, but capital embodied in $x_{1}$ is. Consequently, elasticities of substitution between "taxed capital" and untaxed inputs throughout the economy play such an important part in determining tax incidence. There are more opportunities of substituting untaxed inputs for "taxed capital" here than in an FGO model where only labor can be used for that purpose. In fact, in Harberger's CIT model, factor intensity in the untaxed industry adjusts only if the wage-rental ratio changes. In our hierarchical framework, with a CIT on $x_{1}$, there is really no "untaxed" industry, and relative input costs in $x_{2}$ and $x_{3}$ alter even at an unchanged $w / x$.

\subsubsection{Partial elasticities of substitution: an application}

One interesting application of elasticities of substitution between taxed and untaxed inputs is worth considering. A well-known result for partial factor taxes, derived by Harberger (1962) for CIT is that, in proportion to its initial share in national income, labor can bear more of the tax than capital only if the taxed industry is relatively labor intensive. Here, in equation (13), the capital-labor ratio in the taxed industry does not 
directly appear. Even if $x_{2}$, which uses all of the taxed good in its production, is relatively labor intensive, $r^{*}$ need not be positive, precisely because of substitution elasticities, e.g., when $\sigma_{K L}^{1}, \sigma_{L 1}^{2}$, and $\sigma_{L 2}^{3}$ are sufficiently large. On the other hand, if $x_{2}$ and $x_{3}$ have the same gross capital-labor ratio, $r^{*}$ will be positive if labor cannot be substituted for capital in the taxed industry or for the intermediate goods in the other two, but if all intermediate goods must be used in fixed proportions, $r^{*}$ will be unambiguously negative. In general, if the taxed industry is relatively labor intensive, it will help to make ${ }^{*}$ positive, but it is neither necessary nor sufficient. 8

These conclusions can be explained by observing that the tax being considered here creates three taxed inputs in the production hierarchy: capital in the first industry to which it directly applies, $x_{1}$ which becomes a taxed input for $x_{2}$, and $x_{23}$, used for producing $x_{3}$. The tax is carried over to $x_{2}$, and thence to $x_{3}$ by production linkages. As firms try to switch from taxed to untaxed inputs, there will be greater demand for both labor and untaxed capital if technology permits such substitution. Labor is likely to suffer if it cannot be substituted for the taxed inputs. In fact, large values of $\sigma_{\mathrm{K} 1}^{2}$ and $\sigma_{\mathrm{K} 2}^{3}$ might be sufficient to make $r^{*}$ positive irrespective of factor intensities and other elasticities of substitution.

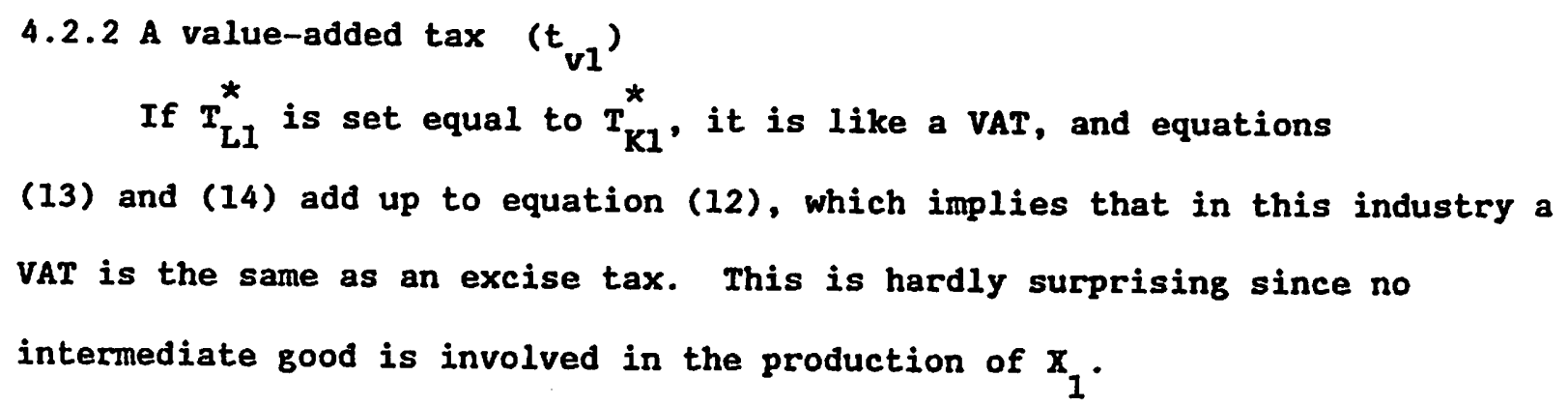




\subsection{Taxes in $\mathrm{x}_{2}$}

For estimating incidence of individual taxes, this industry is the most challenging because it has both backward and forward linkages, and no such good has been looked at so far in a general, flexible tax model. Among the examples of hierarchical production mentioned in the introduction, gasoline is this type of a good: it is refined from a PIG, crude oil, with both final (fuel for pleasure vehicles) and intermediate uses (fuel for trucks). Existing i-o models do have goods which satisfy both intermediate and final demand, and PIG models have final goods that use pure intermediate products. One interesting issue, therefore, is to ask how incidence of taxes in this industry will compare with the results in earlier work. Will significant errors occur if, following earlier analytical work, gasoline is treated as a final good, in an i-o framework, or in a PIG model? This question becomes particularly important if all the elasticities of substitution needed for solving a hierarchical model cannot be precisely estimated.

The first equations to be affected by various taxes will be those for $p_{2}^{*}$ and $p_{3}^{*}$. Beyond that, an excise tax will have no direct bearing on input choices in $x_{1}$ or $x_{2}$, but most definitely in $x_{3}$, although $\sigma^{2}$ will not appear in the tax terms of expressions for $R_{L 3}^{*}$ and $R_{K 3}^{*}$. For example,

$$
\mathrm{R}_{\mathrm{L} 3}^{*}=\left[B_{3}+\rho_{23}\left(B_{2}+\rho_{12} \alpha_{1}\right)\right] r^{*} / \theta_{L 2}-A_{3} T_{2}^{*}
$$

$A_{3}$, as defined above, involves two elasticities of substitution, $\sigma_{L 2}^{3}$ and $\sigma_{\mathrm{K} 2}^{3}$, so the tax affects input choices in $x_{3}$ only if labor and/or capital can be substituted for the taxed good, unless $w / r$ changes. By 
contrast, a factor tax will affect input ratios in both $x^{2}$ and $x^{3}$, and all elasticities of substitution in $x^{2}$ will play a part. The model can be solved for $\mathbf{r}^{\star}$ as before.

Excise $\operatorname{tax}\left(t_{2}\right)$

$$
I^{*}=\frac{\varepsilon\left(1-\rho_{23}\right) F+\lambda_{L 3} \lambda_{K 3} A_{3} / \theta_{L 3} \theta_{K 3}}{D} T_{2}^{*}
$$

Tax on capital in $x_{2}\left(t_{K 2}\right)$

$\mathbf{r}^{*}=\left[\varepsilon p_{\mathrm{K} 2}\left(1-\rho_{23}\right) F-B G+p_{\mathrm{K} 2} A_{3} \lambda_{\mathrm{L} 3} \lambda_{\mathrm{K} 3} / \theta_{\mathrm{L} 3} \theta_{\mathrm{K} 3}\right] \mathrm{T}_{\mathrm{K} 2}^{*} / \mathrm{D}$

where $G=\rho_{K 2}\left(\rho_{12} \rho_{L 1} \sigma_{K 1}^{2}+\rho_{L 2} \sigma_{K L}^{2}\right)$

Tax on labor in $x_{2}\left(t_{L 2}\right)$

$r^{*}=\left[\varepsilon \rho_{\mathrm{L} 2}\left(1-\rho_{23}\right) \mathrm{F}+\mathrm{BH}+\rho_{\mathrm{L} 2} \mathrm{~A}_{3} \lambda_{\mathrm{L} 3} \lambda_{\mathrm{K} 3} / \theta_{\mathrm{L} 3}{ }_{\mathrm{K} 33}\right] \mathrm{T}_{\mathrm{L} 2}^{*} / D$

where

$$
H=\rho_{L 2}\left(\rho_{12} \rho_{K 1} \sigma_{L 1}^{2}+\rho_{K 2} \sigma_{K L}^{2}\right)
$$

$$
\begin{aligned}
& \text { A VAT in } X_{2}\left(t_{V 2}\right) \\
& \text { If } T_{K 2}^{*}=T_{L 2}^{*} \text {, we get a VAT, as before, and } \\
& r^{*}=\left[\varepsilon\left(\rho_{L 2}+\rho_{K 2}\right)\left(1-\rho_{23}\right) F-B A_{2}+\left(\rho_{L 2}+\rho_{K 2}\right) A_{3} \lambda_{L 3} \lambda_{K 3} / \theta_{L 3} \theta_{K 3}\right] T_{V 2}^{*} / D
\end{aligned}
$$




\subsubsection{Comparison with Taxes in $\mathrm{X}_{1}$}

Notice, first of all, that all the solutions for $r^{*}$, except for VAT, are simpler than those for taxes in $x_{1}$. With all taxes, $\sigma^{1}$ terms do not show up in the numerators of $r^{*}$, and in case of excise tax, even $\sigma^{2}$ is missing from the numerator of (16). The denominator, D, of course, is common to all taxes. A VAT in $x_{1}$ is the same as an excise tax, but it is not so here. That explains why (19) is more complicated than equation (11) or even (16), which stems from an excise tax on $x_{2}$.

Comparing factor taxes in $x_{1}$ and $x_{2}$, considering again a tax on capital for brevity, it is clear from (17) that whenever $x_{2}$ is relatively capital intensive $(F>0), r^{*}$ will be negative if $A_{3} \leq 0$. This is somewhat stronger than Result 1 above because there both $A_{3}$ and $A_{2}$ had to be zero or negative. In fact, with $F>0, \sigma_{K 2}^{3}=0$ will be sufficient to make $r^{*}$ $<0$ in equation (17). Turning to other propositions, the second result there will apply here exactly, and the third will hold if $\sigma_{\mathrm{K} 2}^{3}$ is zero, without any restriction on $\sigma_{K 1}^{2}$. Regarding the possibility of a positive $r^{*}$, here also it is not necessary that $x_{2}$ should be labor intensive although it would help.

\subsubsection{Comparison with intermediate good models}

A basic result for an i-o model derived by Bhatia (1982) is that if intermediate goods must be used in fixed proportions, incidence of various taxes depends on the same variables as in an FGO model. That might not happen here because there is a possibility that, unlike an i-o model, the present hierarchical structure will not rank capital-labor ratios in different industries in the same way as an FGO model. This point is illustrated below for an excise tax on $x_{2}$, although it applies equally to factor taxes as well. 
When all elasticities of substitution involving intermediate goods are zero, equation (16) reduces to $r^{*}=c\left(1-\rho_{23}\right) \mathrm{FT}_{2}^{*} / D$. For a similar tax in an i-o model (equation (51) in Bhatia (1982), in comparable notation), $r^{*}=\varepsilon\left(1-P_{23}\right) F^{\prime} Y T_{2}^{*} / D^{\prime}$. Elasticity of demand, $\varepsilon, P_{23}$, and $T^{*}$ are the same in the two expressions, $\gamma>0$, and $D$ and $D^{\prime}$ are positive, so the sign of $r^{*}$ depends on $F$ and $F^{\prime}$, both of which are based on total factor usage. Now, as discussed in Section 2.1 above, $F$ and $F^{\prime}$ can have opposite signs so that $r^{*}$ could be positive in one case and negative in the other. FGo and i-o models must rank industries identically, which accounts for the basic result mentioned in the previous paragraph, but that need not happen under hierarchical technology. Magnitude of $r^{*}$, of course will generally not be the same even in this restrictive setting because $D$ and $D^{\prime}$ will be different. Apart from this important distinction, many results derived in an i-o model will apply here as well. Once again, the taxed industry need not be labor intensive for $r^{*}$ to be positive in case of a partial tax on capital. Large values of elasticity of substitution between capital and the intermediate good in the untaxed final good industry will be sufficient to bring about this outcome even if the taxed industry is relatively capital intensive. Notice, however, that in equation (17), elasticity of substitution in $x_{1}$, which is the only "untaxed" industry in the present context, will have no effect on the sign of $r^{*}$. In this regard, forward linkage seems to be more important than a backward linkage.

In a PIG model, incidence of an excise tax levied on a commodity which uses a pure intermediate product depends on elasticity of demand and (gross) capital labor ratios. The hierarchy here adds nothing new in this regard, its novelty lies in introducing elasticities of substitution into the 
expressions for $r^{\star}$. These os emanate from the intermediate usage of a portion of $x_{2}$, and since that has not been modeled in any existing study involving PIGs, further comparisons along these lines are not very meaningful. For factor taxes, elasticities of substitution between the taxed factor and the intermediate good have similar effects on the final results in the two types of models, but in a PIG model, elasticities of substitution in the untaxed industries do not affect the sign of $r^{*}$ whereas here they do: for example, os in $x_{3}$ will affect the sign of $r^{*}$ in equation (17). 9

The main implication of this analysis for tax incidence studies is that it is hazardous to appply results from an i-o model simply because the taxed final good industry has intermediate uses also. Similarly, borrowing the cpnclusions of a PIG model because a final good happens to need a pure intermediate input also has its pitfalls. If factor intensities have been computed correctly, expressions derived in an i-o model will generally yield the correct sign of $r^{*}$ for taxes levied on, say, gasoline in our example, especially if there is reason to believe that intermediate goods are used in fixed proportions in activities with which the taxed industry has a forward linkage. Greater care is needed in dealing with results derived in a PIG model because both the sign and magnitude of $\mathbf{r}^{*}$ could be wrong. For example, with CIT, if the taxed industry is not relatively labor intensive in terms of total factor usage, $\mathbf{r}^{*}$ will be negative (Bhatia (1982)). In equation (17), no such condition on factor intensities is necessary or sufficient for $r *$ to bẹ negative, although, $r^{*}$ will be unambiguously negative if $F \geq 0$ and capital cannot be substituted for the intermediate good in $x_{3}\left(A_{3}<0\right)$. The crucial requirement here is in terms of $\sigma_{\mathrm{K} 2}^{3}$, rather than about 
capital-labor ratios, for a sufficiently large value of $\sigma_{\mathrm{K} 2}^{3}$ will make $r^{*}$ positive even when the taxed industry is relatively capital intensive. By contrast, recall that, as noted in the introduction, in an FGo model, a necessary condition for positive $r^{*}$ is a relatively labor intensive taxed industry (Harberger (1962), Result 1).

\subsection{Taxes in $\mathrm{x}_{3}$}

This industry is at the very top of the production hierarchy. It has only backward linkages, so it is really the same as a final good in a PIG model analyzed in Bhatia (1982) even though $x_{3}$ does not directly use the only pure intermediate good, $\mathrm{x}_{1}$. Two general principles of tax incidence in such models are: (i) factor intensities have to be reckoned in terms of total usage, rather than in terms of labor and capital directly employed in each industry, and (ii) elasticities of substitution in any industry other than the one subject to a tax do not affect the direction of change in the wage-rental ratio. As noted earlier, factor intensities can be ranked differently in gross and net terms in a PIG model as well as in the present hierarchical framework; consequently, the results reported in Bhatia (1982) also apply here exactly. Magnitude of $\mathrm{r}^{*}$, however, will not be the same in the two cases because of the many additional terms in the denominator of $r *$ which reflect the more complex production structure of a hierarchy. For comparability with earlier results, the final equations for $r^{\star}$ are given below:

$$
\begin{aligned}
& \text { Excise } \operatorname{Tax} \text { in } x_{3} \\
& r^{*}=\varepsilon F T_{3}^{*} / D
\end{aligned}
$$




\section{Tar on Gapital in $z_{3}\left(t_{\mathrm{K} 3}\right)$}

$\mathbf{r}^{*}=-\left[\varepsilon \rho_{\mathrm{K} 3} F+\rho_{\mathrm{K} 3} c_{1} \lambda_{\mathrm{L} 3} \lambda_{\mathrm{K} 3}{ }^{\prime \theta_{\mathrm{L} 3}} \theta_{\mathrm{K} 3}\right] \mathrm{T}_{\mathrm{K} 3}^{\star} / \mathrm{D}$

where

$C_{1}=\rho_{23} \theta_{L 2} \sigma_{\mathrm{K} 2}^{3}+\rho_{\mathrm{L} 3} \sigma_{\mathrm{KL}}^{3}$

Tax on labour in $x_{3}\left(t_{\mathrm{L} 3}\right)$

$r^{*}=-\left[\varepsilon \rho_{L 3} F-\rho_{L 3} c_{2} \lambda_{L 3} \lambda_{\mathrm{K} 3} / \theta_{\mathrm{L} 3} \theta_{\mathrm{K} 3}\right] \mathrm{T}_{\mathrm{L} 3}^{*} / \mathrm{D}$

where

$C_{2}=\rho_{23} \theta_{K 2} \sigma_{L 2}^{3}+\rho_{K 3} \sigma_{K 2}^{3}$

Value-added $\operatorname{tax}$ in $x_{3}\left(t_{v 3}\right)$

$\mathbf{r}^{*}=-\left[\varepsilon F\left(\rho_{\mathrm{L} 3}+\rho_{\mathrm{K} 3}\right)+A_{3} \lambda_{\mathrm{L} 3} \lambda_{\mathrm{K} 3} / \theta_{\mathrm{L} 3} \theta_{\mathrm{K} 3}\right] \mathrm{T}_{\mathrm{V} 3}^{*} / D$

All these expressions are simpler than those for corresponding taxes in $x_{2}$. In particular, no elasticities of substitution in $x_{1}$ or $x_{2}$ affect the sign of $r^{*}$.

\subsection{Tax-incidence Results: Some Common Elements}

Some broad principles which govern incidence of various taxes in a hierarchical model can now be identified.

1. As in any model with intermediate goods, there is a distinction between gross and net factor intensities which affects most of the results, and elasticities of substitution play a pivotal part in determining tax incidence. In both these respects, however, the hierarchical model is different from other models, which leads to a number of new results.

2. So far as factor ratios are concerned, the present framework is like a PIG model: an industry can be relatively capital intensive in terms of labor and capital directly employed by it, but labor intensive when indirect usage 
is also considered. The role of os, however, is like that in an i-o model for the most part. Results which mainly depend on elasticities of substitution, therefore, are similar to those in an i-o model, and where factor-intensities dominate, the conclusions are closer to those derived in a PIG model.

3. Backward linkages do not affect the sign of $r^{*}$, except insofar as they are included in calculating gross capital-labor ratios. In the solutions for taxes in $x_{3}$, for example, no elasticities of substitution from $x_{1}$ or $\mathrm{x}_{2}$ appear in the numerator for $r^{*}$. Likewise, in case of taxes in $x_{2}$, $\sigma_{\mathrm{KL}}^{1}$ is nowhere in the numerator of $r^{*}$. of course, all elasticities of substitution are included in the denominator, $D$, where they affect the magnitude of change in the wage-rental ratio.

4. The direction of change in the wage-rental ratio is strongly affected, and in some cases totally determined, by elasticities of substitution in industries with which taxed activities have forward linkages. This point applies most strongly whenever demand is inelastic or the two final goods have the same gross capital-labor ratio $(\varepsilon=F=0)$, for in these cases only the o-terms remain in the expressions for $r^{*}$.

5. Hierarchical technology for the most part creates a range of effective tax rates for any given tax because of additional stages in production. A commodity tax on $x_{1}$, for example, even at unchanged $w$ and $r$, shows up at two different effective rates in making input choices in the two final-good industries. The same tax in a two-factor-three-commodity PIG model will create an equal distortion for the two final goods, and in a two-good i-o framework, input ratios in only one of the industries will be affected by it. $^{10}$ 
Almost all the results presented in this paper reflect these common elements in one form or another. The most important point for tax-incidence analysis perhaps is the second one above, which distinguishes this framework from related models and leads to several new results. In several cases discussed earlier, elasticities of substitution are like those in an i-o model, yet capital-labor-ratio ranks are reversed, so both the sign and magnitude of $r *$ turn out to be very different. Similarly, in some instances, the results are similar to those in a PIG model vis-a-vis capital-labor ratios, but additional elasticities of substitution come into play.

\section{Summary and Conclusions}

This paper sets up a simple hierarchical model of production to analyze the incidence of a number of factor and commodity taxes. Production hierarchies characterize many industries, yet they have not been used much in rigorous analysis of tax incidence in the literature. In every case, only one factor of production, labor, has been allowed, and there have been restrictions on elasticities of substitution and demand. Consequently, there are not many general results, especially for factor taxes. The structure of production here has a pure intermediate good, a final good, and a third good which serves both final and intermediate uses. Not surprisingly, it incorporates some features of a PIG model and others of an i-o model.

In a hierarchical structure, effects of taxes levied anywhere are carried over to every activity with which the taxed industry has a backward or forward linkage. That generates several new results about tax incidence emanating mostly from possibilities of substituting untaxed for taxed inputs throughout the economy. These results contrast sharply with those derived in 
FGO models, and in some cases even with the results in PIG and $i-0$ models. For empirical studies of tax incidence, the analysis in this paper has two main implications: Firstly, elasticities of substitution in different industries play different roles, and if all of them cannot be estimated precisely, one can at least get some idea of the errors involved. In general, the direction of change in the wage-rental ratio will be affected by substitution elasticities in industries with which a taxed industry has a forward linkage. So long as these are being estimated correctly, the sign of (w* $-r^{*}$ ) will be correct. Secondly, expressions derived in other related models ordinarily will not apply to a production hierarchy even though the same type of goods appear in many of them. If there is no problem in computing factor intensities, results in i-o models will give a good idea of what to expect in hierarchical models of the type set up here, but there will be difficulties in applying the results of a PIG model even though the hierarchy here incorporates a key feature of such models about ranking factor intensities in gross and net terms. 


\section{FOOTNOTES}

${ }^{1}$ An i-o table can be aggregated to a two-sector specification as in Solow (1986), but that entails loss of information and might also lead to inaccurate results.

2 The assumptions underlying this demand function are: (i) all households have identical preferences, (ii) the government spends tax revenue exactly as households would have, and (iii) no taxes in initial equilibrium. This is also the demand function used by Harberger (1962).

${ }^{3}$ Conceptually, these are the same as what Mieszkowski (1967) calls "the output effect" and "the factor substitution effect". Mieszkowski was dealing with an FGO model. As we shall see below, the precise form of these effects is different for different models.

"For each input there is one own-price and two "cross" partial elasticities of substitution, as defined by Allen (1969), and their weighted sum, with factor shares as weights, will be zero for a linear, homogeneous production function. For example, $\rho_{L 2} \sigma_{L L}^{2}+\rho_{K 2} \sigma_{L K}^{2}+\rho_{12} \sigma_{L 1}^{2}=0$.

5 More information about this and other derivations is given in the Appendix.

${ }^{6}$ The proof derives from a stability condition for a linear, homogeneous production function with three inputs, which implies that at most only one cross partial elasticity of substitution can be negative. For more details, see Batra (1974, pp. 178-179).

${ }^{7}$ For this reason, a better comparison might be with a PIG model, but taxes levied on factors used for producing pure intermediate goods have not been considered at all in the literature. The general results presented below, therefore, are of more than casual interest. 
8

${ }^{8}$ since a factor tax in an industry such as $x_{1}$ has not been considered in the literature, the case which comes closest is CIT on a final good in Bhatia (1982) where the model involved two final goods and a pure intermediate good. There the Harberger result held exactly: the taxed industry had to be relatively labor intensive before $r^{*}$ could be positive. We shall return to this point when factor taxes in $x_{2}$ and $x_{3}$ are considered. ${ }^{9}$ It might be argued that with a factor tax in $x_{2}, x_{3}$ is really not an untaxed industry here because of hierarchical technology. Only $\mathrm{x}_{1}$ qualifies, and the sign of $r^{*}$ in (17) does not depend on any elsticities of substitution in that industry. From this standpoint, results in the present model will be closer to those in a PIG model.

${ }^{10}$ One might object that a two-good i-o framework is not strictly comparable with the other two types of models because they have three goods. The common element here is that they all have only two final goods. The point about different effective tax rates nonetheless will apply to more elaborate i-o structures as well. 
REFERENCES

Aaron, H. (1968), "The Differential Price Effects of a Value-added Tax," National Tax Journal 21, 162-175.

Allen, R. G. D. (1969), Mathematical Analysis for Economists (Macmillan, U.K.). Atkinson, A. B. and Stiglitz, J. E. (1980), Lectures in Public Economics (HcGraw-Hil1).

Batra, R. N. (1974), Studies in the Pure Theory of International Trade (Macmillan, U.K.).

Bhatia, K. B. (1981), "Intermediate Goods and the Incidence of the Corporation Income Tax," Journal of Public Economics 16, 93-112. (1982), "Intermediate Goods and the Theory of Tax Incidence," Public Finance $37,318-338$.

Dresch, S. P., Lin, A. and Stout, D. K. (1977), Substituting a Value-added Tax for the Corporate Income Tax (Ballinger, U.S.A.).

Friedlaender, A. F. (1967), "Indirect Taxes and Relative Prices," Quarterly Journal of Economics $81,125-139$.

Fullerton, D., Shoven, J. and Whalley, J. (1978), "General Equilibrium Analysis of U.S. Taxation Policy," in 1978 Compendium of Tax Research, Washington, D.C., 1978 .

Harberger, A. C. (1962), "The Incidence of the Corporation Income Tax," Journal of Political Economy 70, 215-240. (1966), "Let's Try a Value-added Tax," Challenge 15.

HcLure, C. E., Jr. (1981), "VAT Versus the Payroll Tax," in F. Skidmore, ed., Social Security Financing (MIT Press, Cambridge), 129-164.

Mieszkowski, P. M. (1967), "On the Theory of Tax Incidence," Journal of Political Economy 75, 250-262. 
Solow, J.L., (1986), "Interindustry Flows and the Incidence of the Corporation Income Tax", Journal of Public Economy, 259-268.

Vartholomeos, J. (1974), "Price and Trade Effects of the Substitution of a Value-added Tax for the Corporate Income Tax: The British Case," Finanzarchiv $32,469-480$.

Warne, R. D. (1971), "Intermediate Goods in International Trade with Variable Proportions and Two Primary Inputs," Quarterly Journal of Economics 85 , 225-36. 


\section{APPENDIX}

Various $R_{i j}^{*}$ s can be derived as follows:

By definition $\mathrm{R}_{\mathrm{L} 2}=a_{\mathrm{L} 1} \mathbf{a}_{12}+\mathrm{a}_{\mathrm{L} 2}$. Therefore,

$$
R_{L 2}^{*}=\frac{d R_{L 2}}{R_{L 2}}=\left[a_{L 1} a_{12}\left(a_{12}^{*}+a_{L 1}^{*}\right)+a_{L 2} a_{L 2}^{*}\right] / R_{L 2}
$$

and converting to factor shares,

$$
\mathbf{R}_{L 2}^{*}=\left[\rho_{12} \rho_{L 1}\left(a_{12}^{*}+a_{L 1}^{*}\right)+\rho_{L 2} a_{L 2}^{*}\right] / \theta_{L 2}
$$

where $p s$ are factor shares based on direct usage, and $\theta$ s are derived from total usage. Similarly, $R_{L 3}=a_{L 3}+a_{23} R_{L 2}$, which yields

$$
R_{L 3}^{*}=\theta_{L 2} \rho_{23}\left(a_{23}^{*}+R_{L 2}^{*}\right)+\rho_{L 3} a_{L 3}^{*} .
$$

Now, $a_{L 2}=a_{L 2}\left(w, r, p_{1}\right)$. By totally differentiating it we get $\left(w^{*}=0\right)$ :

$$
a_{L 2}^{*}=\left(\rho_{K 2} \sigma_{L K}^{2}+\rho_{12} \rho_{K 1} \sigma_{L 1}^{2}\right) r^{*}
$$

where

$$
\sigma_{L K}^{2}=\frac{1}{p_{L 2}} \frac{\partial a}{\partial w} \frac{w}{a_{K 2}}
$$

Definitions of other os are analogous. The final expressions for $R^{*} s$ are derived by substituting various $a_{i j}^{*} s$ and simplifying. 